\title{
CEP131 knockdown inhibits cell proliferation by inhibiting the ERK and AKT signaling pathways in non-small cell lung cancer
}

\author{
JUNYING WANG $^{1}$, XIAOPING YANG ${ }^{2}$, SHIXIN HAN $^{3}$ and LIZHI ZHANG ${ }^{1}$ \\ ${ }^{1}$ Department of Pathology, The First Affiliated Hospital of Dalian Medical University, Dalian, Liaoning 116011; \\ ${ }^{2}$ Department of Anesthesiology, Dalian Obstetrics and Gynecology Hospital, Dalian, Liaoning 116033; \\ ${ }^{3}$ Department of Dermatology, The First Affiliated Hospital of Dalian Medical University, Dalian, Liaoning 116011, P.R. China
}

Received February 26, 2019; Accepted December 3, 2019

DOI: $10.3892 / \mathrm{ol} .2020 .11411$

\begin{abstract}
Disrupted centrosome-associated family protein expression can result in the detrimental duplication of centrosomes, causing genomic instability and subsequent carcinogenesis. Limited research has demonstrated that centrosomal protein 131 (CEP131) exhibits oncogenic activity in osteosarcoma, hepatocellular carcinoma and breast cancer. The present study demonstrated that there is an association between CEP131 expression and advanced Tumor-Node-Metastasis stage $(\mathrm{P}=0.016)$, and positive regional lymph node metastasis $(\mathrm{P}=0.023)$ in 91 cases of non-small cell lung cancer. A549 and SPC-A-1 cells, with moderate expression levels of CEP131, were selected as representative cell lines. The results indicated that downregulation of CEP131 induced G1/S cell cycle arrest, inhibition of cyclins D1/E and cyclin-dependent kinases 2/4/6, and induction of inhibitory $\mathrm{p} 21 / \mathrm{p} 27$, all of which are regulated by ERK and AKT signaling, suggesting that CEP131 exhibits potential as a novel target in the treatment of lung cancer.
\end{abstract}

\section{Introduction}

Lung cancer is one of the most common and fatal malignancies worldwide, and the histological subtype non-small cell lung cancer (NSCLC) accounts for $\sim 85 \%$ of all cases $(1,2)$. Although certain improvements have been made in surgical treatment, chemotherapy and radiotherapy, the prognoses of patients with NSCLC remain unsatisfactory $(3,4)$; therefore, elucidation of novel approaches for the prevention, early detection and treatment of NSCLC are urgently required.

Centrosome-associated family proteins (CEPs) are the active components of centrosomes and participate in centrosome biogenesis and function (5). Disrupted CEP expression

Correspondence to: Professor Lizhi Zhang, Department of Pathology, The First Affiliated Hospital of Dalian Medical University, 222 Zhong Shan Road, Dalian, Liaoning 116011, P.R. China

E-mail: ailizhil@aliyun.com

Key words: centrosomal protein 131, non-small cell lung cancer, ERK and AKT signaling, proliferation can result in the detrimental duplication of centrosomes, causing genomic instability and subsequent carcinogenesis. Centrosomal protein 131 (CEP131), alternatively named azacytidine-inducible-1, was initially identified in murine spermatid as a pre-acrosome-localized protein, and was subsequently identified more specifically as a novel centrosomal protein in a large-scale proteomic screen (6-8). CEP131 is now understood to be an evolutionarily conserved centriolar satellite protein that exerts a pivotal function in the development and movement of cilia (9). In addition, CEP131 has been demonstrated to be essential for the maintenance of genome stability (10), suggesting a possible role in the development and progression of cancer. Notably, it has been demonstrated that CEP131 is involved in osteosarcoma and breast carcinogenesis via interactions with 14-3-3 and ubiquitin specific peptidase 9 X-linked, respectively (11,12). Additionally, CEP131 exhibits oncogenic activity in hepatocellular carcinoma (13). However, the precise roles and molecular mechanisms of CEP131 in NSCLC remain unclear.

The present study aimed to explore the role of CEP131 in NSCLC transformation and progression. The present study demonstrated that CEP131 overexpression in NSCLC tissues is associated with advanced Tumor-Node-Metastasis (TNM) stage and positive regional lymph node metastasis. Furthermore, CEP131-knockdown was demonstrated to inhibit NSCLC cell proliferation in vitro by inhibiting the ERK and AKT signaling pathways and their downstream signals.

\section{Materials and methods}

Patients and specimens. The present study was approved by the Institutional Review Board of Dalian Medical University. Written informed consent was obtained from the patients. NSCLC tissue samples were obtained from 91 patients (65 males and 26 females) who underwent complete surgical excision of squamous cell carcinoma or adenocarcinoma at the First Affiliated Hospital of Dalian Medical University (Dalian, China) during the period between January 2014 and January 2016. No neoadjuvant radiotherapy or chemotherapy was applied prior to surgery. The mean age of the patients was 62 years (range, 39-83 years). Histological classification and lung cancer differentiation were evaluated according to 2015 World Health Organization classification criteria, and TNM 
staging of lung cancer was performed according to the 2009 Union for International Cancer Control standard (14).

Immunohistochemical staining. Surgically excised NSCLC specimens were fixed in $10 \%$ neural formalin overnight at room temperature and then embedded in paraffin. Subsequently, 4- $\mu$ m-thick sections were prepared, and immunostaining was performed using the UltraSensitive ${ }^{T M} S P$ kit (cat. no. KIT-9720; Fuzhou Maixin Biotech Co., Ltd.) according to the manufacturer's protocol. Tissue sections were incubated with a CEP131 rabbit polyclonal antibody (cat. no. ab84864, Abcam) overnight at $4^{\circ} \mathrm{C}$, and PBS was used as the negative control. All tumor slides were randomly examined by two independent investigators from the Department of Pathology of The First Affiliated Hospital of Dalian Medical University (Dalian, China). A total of 100 cells were examined at x400 magnification in five randomly selected fields of view per slide. CEP131 expression was semi-quantitatively scored according to the percentage of expressing cells and staining intensity. The staining intensity was scored as 0 (negative), 1 (weak) or 2 (marked), and percentage scores were allocated as 1 (1-25\%), $2(26-50 \%), 3(51-75 \%)$ and 4 (76-100\%). Scores for each tumor sample were multiplied to give a final score between 0 and 8 . CEP131 status was regarded as low expression (score $<4$ ) or high expression/overexpression (score $\geq 4$ ).

Cell culture. The A549 and SPC-A-1 cell lines were purchased from the Cell Bank of Type Culture Collection of the Chinese Academy of Sciences. All cells were cultured in RPMI-1640 medium (Invitrogen; Thermo Fisher Scientific, Inc.) supplemented with $10 \%$ fetal bovine serum (Invitrogen; Thermo Fisher Scientific, Inc.), $100 \mathrm{IU} / \mathrm{ml}$ penicillin (Sigma-Aldrich: Merck $\mathrm{KGaA}$ ) and $100 \mu \mathrm{g} / \mathrm{ml}$ streptomycin (Sigma-Aldrich; Merck $\mathrm{KGaA})$ at $37^{\circ} \mathrm{C}$ and $5 \% \mathrm{CO}_{2}$. Cells were passaged every 2 days by trypsinization (0.25\%; Invitrogen; Thermo Fisher Scientific, Inc.).

Transfection. CEP131-small interfering RNA (siRNA; cat. no. sc-94024) and negative control (NC)-siRNA (cat. no. sc-37007) were obtained from Santa Cruz Biotechnology, Inc. A549 and SPC-A-1 cells were transfected with these siRNAs using Lipofectamine ${ }^{\circledR} 3000$ (Invitrogen; Thermo Fisher Scientific, Inc.), according to efficiency by western blotting. The siRNA sequences used in the experiment were: siRNA-CEP131, 5'-GGAGGAGAAGGCACGCCA ATT-3'; siRNA-NC, 5'-UUCUCCGAACGUGUCACGUTT-3'. Subsequent experiments were performed using cells collected $48 \mathrm{~h}$ post-transfection.

MTT assay. Following transfection with CEP131 siRNA, A549 and SPC-A-1 cells were cultured on 96-well plates, and cell viability was quantitated after 4 days using the MTT assay. A $20-\mu 1$ aliquot of MTT $(5 \mathrm{mg} / \mathrm{ml})$ solution was added to each well and incubated for $4 \mathrm{~h}$ at $37^{\circ} \mathrm{C}$. Following incubation, the resulting formazan crystals were dissolved in DMSO (150 $\mu \mathrm{l} /$ well). The absorbance was measured spectrophotometrically at a wavelength of $490 \mathrm{~nm}$. Experiments were performed in triplicate.

Flow cytometry. A549 and SPC-A-1 cells were seeded onto $6-\mathrm{cm}$ dishes at $30-50 \%$ confluence, and subsequently transfected with CEP131-siRNA or NC-siRNA. Cells were harvested $48 \mathrm{~h}$ following transfection and stained using the Cell Cycle Staining kit (cat. no. WLA010; Wanleibio Co., Ltd.), according to the manufacturer's protocol. DNA content was determined by flow cytometry (BD Biosciences). Cell cycle analysis was modeled using Modfit version 3.2 (Verity Software House, Inc.). Each experiment was repeated three times. The results are presented as the percentage of the total cell count in different phases of the cell cycle, namely $G_{1}, S$ and $\mathrm{G}_{2}$.

Western blotting. Total protein from the cell lines was extracted using lysis buffer (Pierce; Thermo Fisher Scientific, Inc.), and the protein concentration was determined by the BCA protein assay. A concentration of $60 \mu \mathrm{g}$ per sample was separated by $10 \%$ SDS-PAGE and subsequently transferred to polyvinylidene fluoride (EMD Millipore) membrane. The membranes were blocked with $5 \%$ non-fat milk at room temperature for $1 \mathrm{~h}$ and incubated overnight at $4^{\circ} \mathrm{C}$ with primary antibodies. All primary antibodies were provided by Cell Signaling Technology (Danvers, MA) or Abcam (Cambridge, MA) and the dilutions used in the current study are listed: CEP131 (cat. no. ab84864; 1:100), cyclinD1 (cat. no. CST\#2922; 1:1,000), cyclin E (cat. no. CST\#4132; 1:1,000), cyclin-dependent kinase (CDK) 2 (cat. no. CST\#2546; 1:1,000), CDK4 (cat. no. CST\#12790; 1:1,000), CDK6 (cat. no. CST\#13331; 1:1,000), p21 (cat. no. CST\#2947; 1:1,000), p27 (cat. no. CST\#3686; 1:1,000), MEK1 (cat. no. CST\#9122; 1:1,000), phosphorylated (p)-MEK1/2 (Ser-217/221) (cat. no. CST\#9121; 1:1,000), Erk1/2 (cat. no. CST\#9102; 1:1,000), p-Erk1/2 (Tyr202/Tyr204) (cat. no. CST\#9101; 1:1,000), glycogen synthase kinase-3 $\beta$ (GSK-3 $\beta$ ) (cat. no. CST\#9315; 1:1,000), p-GSK-3 $\beta$ (ser-9) (cat. no. CST\#9336; 1:1,000), p-Akt (Ser-473) (cat. no. CST\#4060; 1:1,000), p-PI3K (Tyr-458) (cat. no. CST\#4228; 1:1,000), PI3K (cat. no. CST\#4292; 1:1,000), and GAPDH (cat. no. CST\#5174; 1:1,000). Membranes were washed three times in PBS and subsequently incubated with peroxidase-conjugated anti-mouse or anti-rabbit IgG (cat. no. sc-2357 and sc-2005, respectively; both 1:4,000; both Santa Cruz Biotechnology, Inc.) at $37^{\circ} \mathrm{C}$ for $2 \mathrm{~h}$. Protein bands were detected using ECL reagent (GE Healthcare) and processed using the ImageJ software (version 1.46; National Institutes of Health).

Statistical analysis. All data were analyzed using SPSS 22.0 software (IBM Corp.). A $\chi^{2}$ test was used for the evaluation of the associations between CEP131 expression levels and patient clinicopathological characteristics. A two-tailed Student's t-test was employed to compare two independent groups. $\mathrm{P}<0.05$ was considered to indicate a statistically significant difference. All experiments were performed in triplicate, and mean values were calculated for data comparison. Data are expressed as the mean \pm standard deviation.

\section{Results}

CEP131 is highly expressed in NSCLC tissues. Immunohistochemistry of 91 NSCLC tissues samples and their corresponding normal tissue samples was performed, which revealed that CEP131 expression levels were markedly higher in malignant tissue when compared with normal lung epithelial 

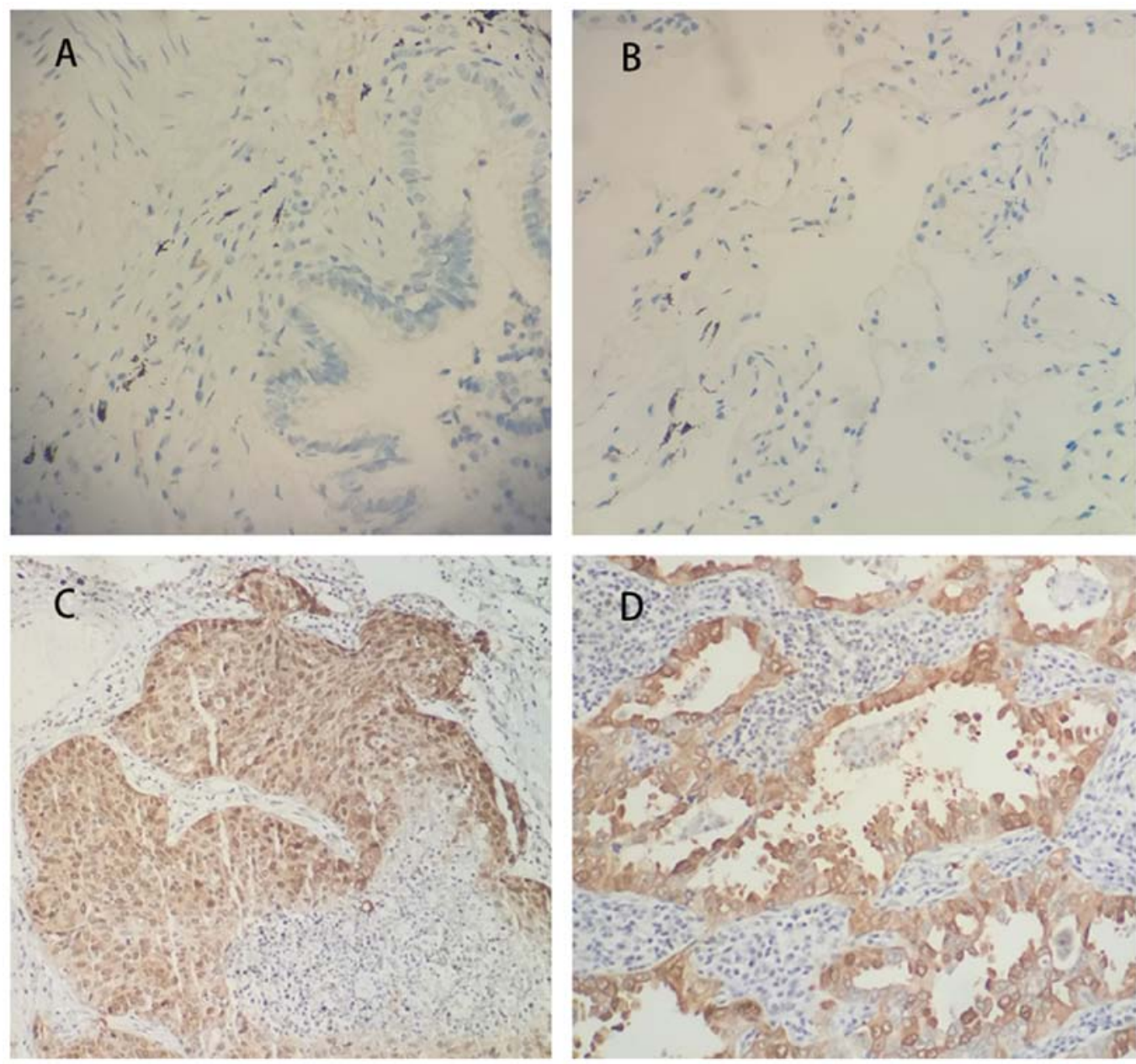

Figure 1. CEP131 expression in NSCLC tissue samples. Negative or weak CEP131 expression in (A) normal bronchial and (B) alveolar epithelial cells. Positive CEP131 expression in the (C) nucleus and cytoplasm of lung squamous cell carcinoma and (D) adenocarcinoma cells. Magnification, x400. CEP131, centrosomal protein 131; NSCLC, non-small cell lung cancer.

cells. Normal bronchial epithelial cells exhibited negative CEP131 staining (Fig. 1A and B); however, CEP131 was overexpressed in cases of NSCLC, primarily in the nucleus and cytoplasm (Fig. 1C and D). As presented in Table I, high CEP131 expression was observed in 63.7\% (58/91) of cases. High CEP131 expression was identified in $65.9 \%$ (27/41) of squamous cell carcinoma cases and $62.0 \%(31 / 50)$ of adenocarcinoma cases. The expression of CEP131 was identified to be significantly associated with TNM stage $(\mathrm{P}=0.016)$ and nodal status $(\mathrm{P}=0.023)$.

CEP131-knockdown inhibits NSCLC cell proliferation. To examine the functional significance of CEP131 in lung cancer cells, the present study utilized siRNA to knockdown CEP131 expression in A549 and SPC-A-1 cell lines, both of which exhibit moderate CEP131 protein expression (15). CEP131-specific siRNA substantially reduced protein expression levels following $48 \mathrm{~h}$ of siRNA treatment (Fig. 2A and B). The proliferation rate was determined by MTT assays. Following transfection with CEP131 siRNA, the proliferation rate of A549 and SPC-A-1 cells was markedly reduced when compared with the negative control (Fig. 3A). Taken together, these finding suggest that CEP131 promotes lung cancer cell proliferation.
CEP131 regulates the cell cycle in NSCLC cells. Since CEP131 knockdown inhibited cell proliferation in A549 and SPC-A-1 cells, the present study subsequently analyzed its effect on the cell cycle using flow cytometry. CEP131 knockdown in A549 and SPC-A-1 cells significantly increased the percentage of cells in the G1 phase but significantly decreased the percentage in the $\mathrm{S}$ phase (Fig. 3B). No significant changes were detected in the $\mathrm{G} 2$ phase. The present study also examined the expression of cell cycle-associated proteins in CEP131-downregulated cells. Western blotting analysis revealed associations between CEP131 protein expression in NSCLC tissue and that of cell cycle-related regulatory proteins, including cyclin D1, cyclin E, CDK2, CDK4, CDK6, p21 and p27. These data demonstrate that the expression levels of cyclin D1, cyclin E, CDK2, CDK4, and CDK6 are reduced and those of p21 and p27 are elevated in CEP131-downregulated cells (Fig. 3C). Taken together, these data suggest that CEP131 promotes cell cycle progression via an increase in the expression of cell cycle-promoting proteins and a reduction in the expression of cell cycle-inhibiting proteins.

CEP131 promotes the cell cycle through the ERK and AKT signaling pathways. The ERK and PI3K/Akt signaling pathways are well-known upstream factors that regulate 
Table I. Association of CEP131 expression and clinicopathological parameters in 91 cases of NSCLC.

\begin{tabular}{|c|c|c|c|c|c|}
\hline \multirow[b]{2}{*}{ Characteristics } & \multirow[b]{2}{*}{ No. of patients } & \multicolumn{2}{|c|}{ CEP131 } & \multirow[b]{2}{*}{$\chi^{2}$-value } & \multirow[b]{2}{*}{ P-value } \\
\hline & & Low expression & High expression & & \\
\hline \multicolumn{6}{|l|}{ Age, years } \\
\hline$<60$ & 32 & 13 & 19 & 0.406 & 0.524 \\
\hline$\geq 60$ & 59 & 20 & 39 & & \\
\hline \multicolumn{6}{|l|}{ Sex } \\
\hline Male & 65 & 22 & 43 & 0.575 & 0.448 \\
\hline Female & 26 & 11 & 15 & & \\
\hline \multicolumn{6}{|l|}{ Histology } \\
\hline Adenocarcinoma & 50 & 19 & 31 & 0.145 & 0.704 \\
\hline Squamous cell carcinoma & 41 & 14 & 27 & & \\
\hline \multicolumn{6}{|l|}{ Differentiation } \\
\hline Well + Moderate & 60 & 23 & 37 & 0.326 & 0.568 \\
\hline Poor & 31 & 10 & 21 & & \\
\hline \multicolumn{6}{|l|}{ TNM stage } \\
\hline $\mathrm{I}$ & 54 & 25 & 29 & 5.784 & $0.016^{\mathrm{a}}$ \\
\hline II+III & 37 & 8 & 29 & & \\
\hline \multicolumn{6}{|l|}{ Lymph node metastasis } \\
\hline Positive & 39 & 9 & 30 & 5.135 & $0.023^{\mathrm{a}}$ \\
\hline Negative & 52 & 24 & 28 & & \\
\hline
\end{tabular}

${ }^{a} \mathrm{P}<0.05$ was considered significant. CEP131, centrosomal protein 131; TNM, Tumor-Node-Metastasis; NSCLC, non-small cell lung cancer.

A

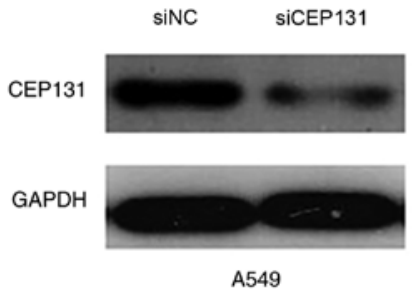

B

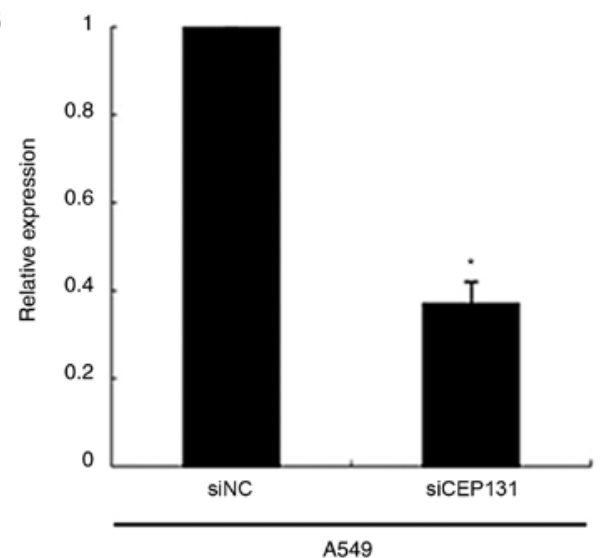

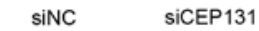
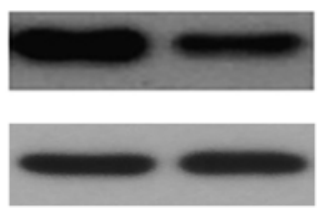

SPC-A-1

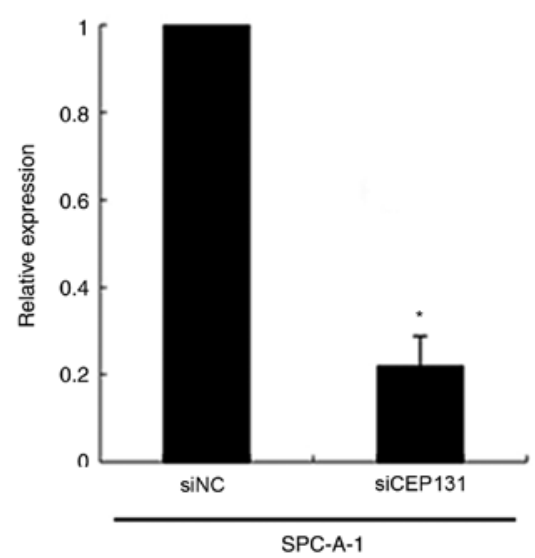

Figure 2. CEP131 depletion in A549 and SPC-A-1 cell lines. (A) Western blotting assays for detecting CEP131 protein expression levels in A549 and SPC-A-1

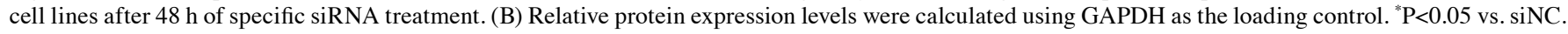
siRNA, small interfering RNA; siNC, small interfering negative control; CEP131, centrosomal protein 131.

the cell cycle $(16,17)$. The expression levels of ERK- and PI3K/Akt-related proteins were detected by western blotting.
Densitometric analysis was performed on phospho-target protein bands and normalized to the total expression of 
A
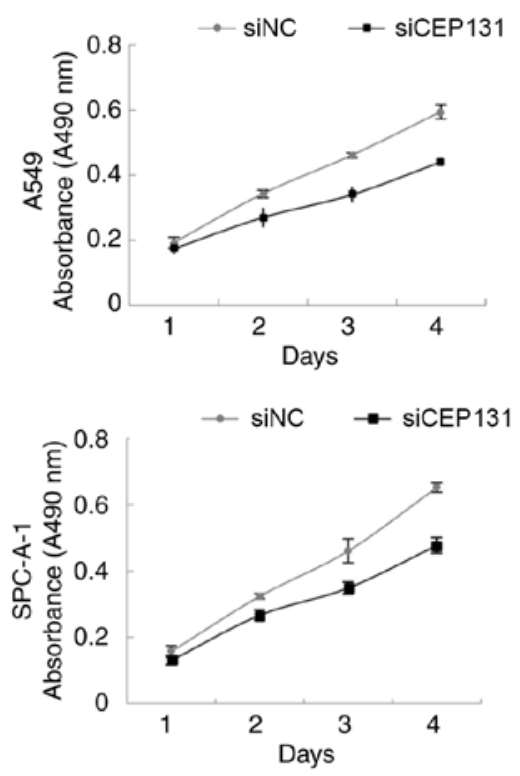

B
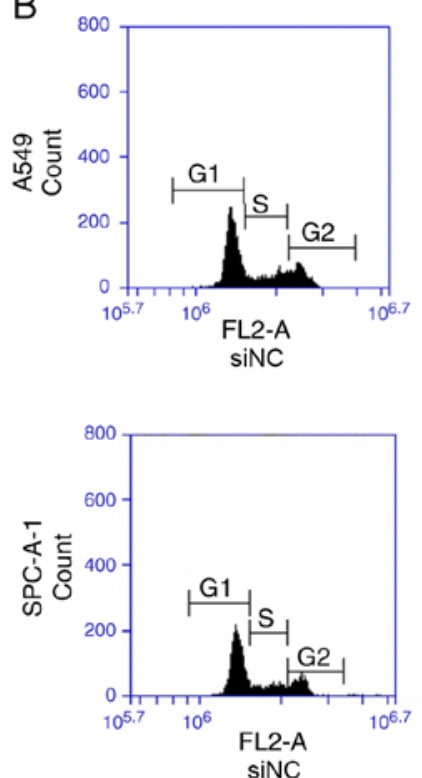
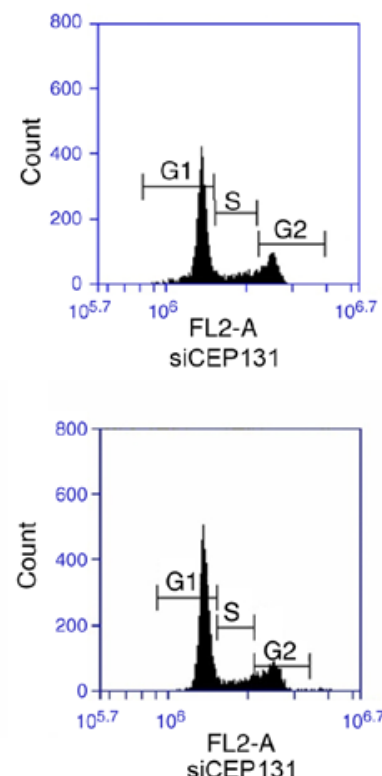

C
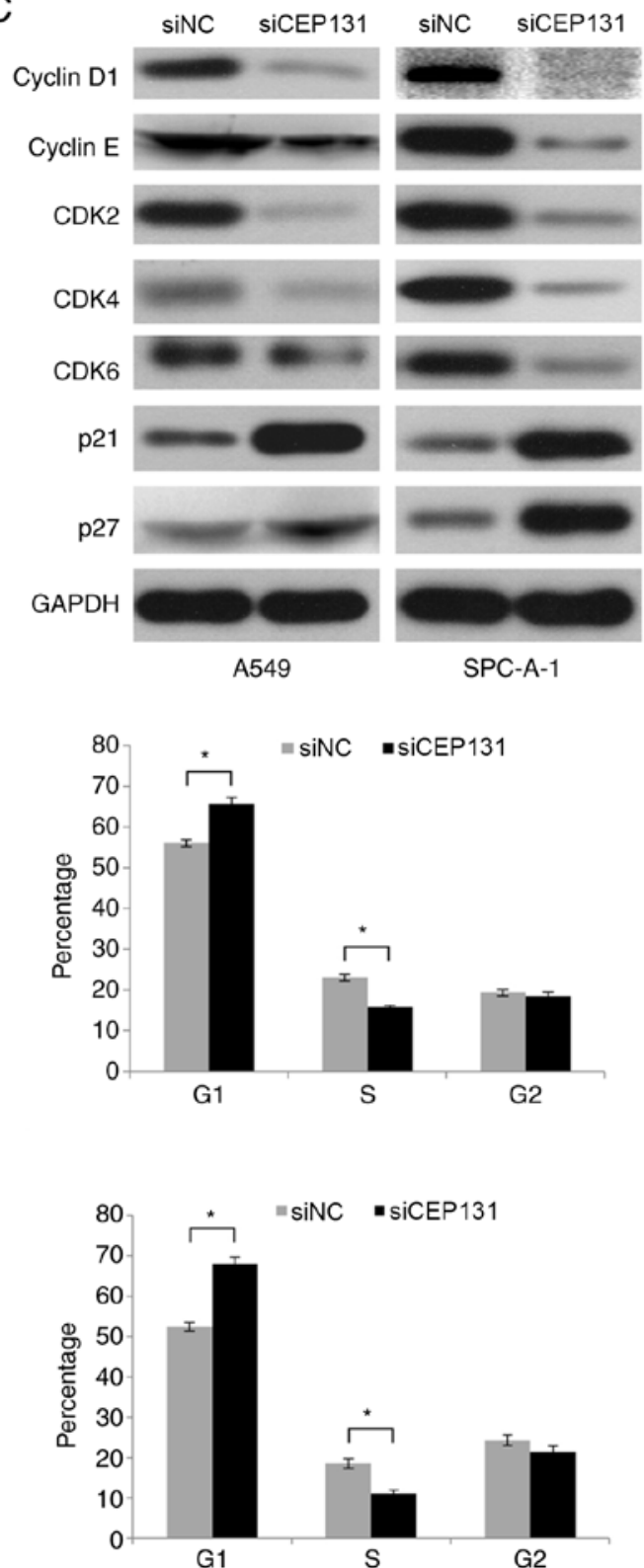

Figure 3. CEP131 knockdown inhibits cell proliferation and induced cell cycle arrest. (A) In vitro proliferative ability of NSCLC cells was markedly reduced in CEP131-downregulated cells compared with the negative control, as determined by MTT assay. (B) CEP131 knockdown induced G1/S cell cycle arrest. (C) Western blot analysis revealed that the expression levels of cyclin D1, cyclin E, CDK2, CDK4 and CDK6 were reduced, and the expression levels of p21 and p27 are elevated in CEP131-downregulated cells. " $\mathrm{P}<0.05$. NSCLC, non-small cell lung cancer; siRNA, small interfering RNA; siNC, small interfering negative control; CEP131, centrosomal protein 131.

the corresponding protein and GAPDH (Fig. 4). Data are presented as the mean \pm standard deviation of three independent experiments. A value of 1 was arbitrarily assigned to the ratio obtained in the negative control group. Knockdown of CEP131 expression in A549 and SPC-A-1 cells resulted in a significant decrease in the expression levels of p-PI3K (Tyr458) (0.51 $\pm 0.11 ; 0.52 \pm 0.08)$, p-Akt (Ser473) (0.60 \pm 0.09 ; $0.58 \pm 0.12)$, p-MEK1/2 (Ser-217/221) $(0.55 \pm 0.04 ; 0.70 \pm 0.03)$, p-Erk1/2 (Tyr202/Tyr204) $(0.58 \pm 0.24 ; 0.68 \pm 0.16)$, and p-GSK-3 $\beta$ (ser-9) $(0.57 \pm 0.18 ; 0.63 \pm 0.09)$ compared with the negative control $(\mathrm{P}<0.05$; Table II). These results demonstrate that CEP131 promotes NSCLC cell proliferation, at least partly, via the activation of the ERK and PI3K/Akt signaling pathways and their downstream effectors.

\section{Discussion}

CEP131 is a relatively recently discovered protein whose expression pattern and role in NSCLC progression were previously unknown. The present study demonstrated that CEP131 is highly expressed in the nucleus and cytoplasm of NSCLC cells. CEP131 overexpression was revealed to be associated with advanced TNM stage and positive lymph node metastasis, but not with patient age, sex, tumor differentiation or histopathology. Statistical analyses demonstrated that no association exists between CEP131 expression and tumor differentiation grade in either adenocarcinoma or squamous cell carcinoma. Results of the MTT and cell cycle assays demonstrated that, in addition to regulating cell proliferation and cell cycle progression, CEP131 
Table II. Ratio of phosphorylated protein levels to total protein levels.

\begin{tabular}{|c|c|c|c|c|c|c|}
\hline \multirow[b]{2}{*}{ Phosphorylated/total protein } & \multicolumn{2}{|c|}{ A549 } & \multirow[b]{2}{*}{ P-value } & \multicolumn{2}{|c|}{ SPC-A-1 } & \multirow[b]{2}{*}{ P-value } \\
\hline & siNC & siCEP131 & & siNC & siCEP131 & \\
\hline p-AKT/AKT & 1 & $0.60 \pm 0.09$ & $0.003^{\mathrm{a}}$ & 1 & $0.58 \pm 0.12$ & $0.017^{\mathrm{a}}$ \\
\hline p-MEK1/2/MEK1 & 1 & $0.55 \pm 0.04$ & $0.008^{\mathrm{a}}$ & 1 & $0.70 \pm 0.03$ & $0.013^{\mathrm{a}}$ \\
\hline p-GSK- $3 \beta / G S K-3 \beta$ & 1 & $0.57 \pm 0.18$ & $0.024^{\mathrm{a}}$ & 1 & $0.63 \pm 0.09$ & $0.004^{\mathrm{a}}$ \\
\hline p-ERK1/2/ERK1/2 & 1 & $0.58 \pm 0.24$ & $0.041^{\mathrm{a}}$ & 1 & $0.68 \pm 0.16$ & $0.016^{\mathrm{a}}$ \\
\hline p-PI3K/PI3K & 1 & $0.51 \pm 0.11$ & $0.008^{\mathrm{a}}$ & 1 & $0.52 \pm 0.08$ & $0.004^{\mathrm{a}}$ \\
\hline
\end{tabular}

Relative protein expression levels were calculated using GAPDH as the loading control. Data are presented as the mean \pm standard deviation. ${ }^{a} \mathrm{P}<0.05$ was considered significant. $\mathrm{p}$, phosphorylated; GSK-3 $\beta$, glycogen synthase kinase-3 $\beta$; MEK, mitogen-activated protein kinase kinase 1; CEP131, centrosomal protein 131; siRNA, small interfering RNA; siNC, small interfering negative control.

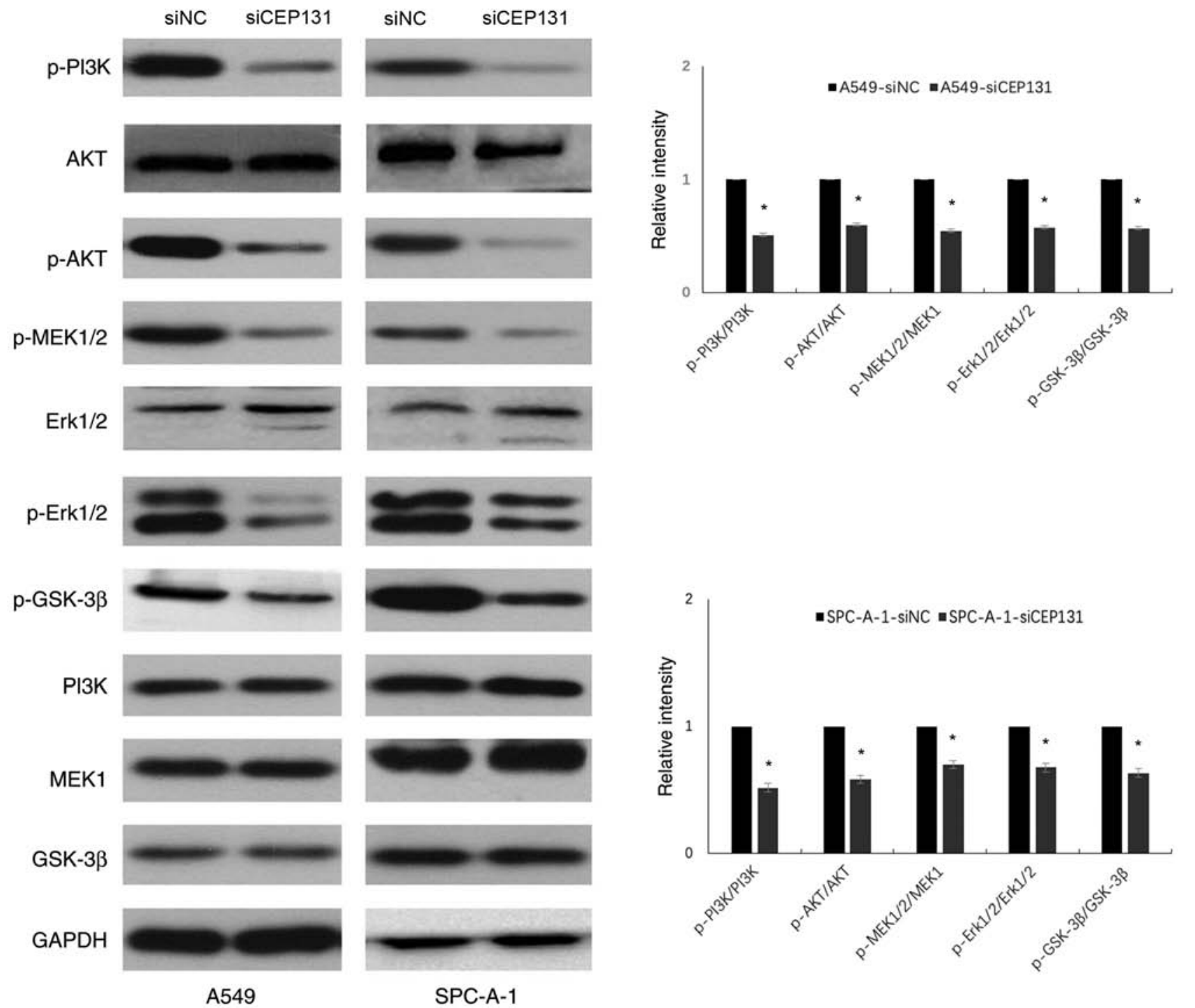

Figure 4. CEP131 regulates ERK and AKT signaling pathways and their downstream effectors. Knockdown of CEP131 expression reduced the expression of p-PI3K (Tyr458), p-Akt (Ser473), p-MEK1/2 (Ser-217/221), p-Erk1/2 (Tyr202/Tyr204) and p-GSK-3ß (Ser-9). The relative protein expression levels were calculated using GAPDH as the loading control. "P<0.05. CEP131, centrosomal protein 131; p-, phosphorylated.

also modulates the expression levels of cell cycle-related proteins. The high proliferation level of tumor cells is known to be associated with increased cell-cycle progression, with cell cycle dysregulation being a prevalent cancer characteristic (18-20). 
Cell cycle distribution is tightly regulated by cyclins, CDKs and cyclin-dependent kinase inhibitors (CDKIs) (21). Progression of the G1 phase is primarily regulated by cyclin D1 and the G1/S transition is enhanced by cyclin E $(22,23)$. Cyclin D1 is one of the most important cell cycle regulators during tumor development, which forms functional kinase complexes with CDK4 and CDK6 to aid transition from the G1 phase to the S phase $(24,25)$. Both p21 and p27 are CDKIs that participate in cell-cycle regulation via the inhibition of cyclin-CDK complex activity in the G1 phase (26). The present data indicates that the downregulation of CEP131 induces G1/S cell cycle arrest by inhibiting cyclins D1/E and CDK 2/4/6 and inducing inhibitory p21/ p27. Therefore, it was concluded that CEP131 regulates tumor proliferation via the cell cycle regulation.

The present study screened key signaling proteins, such as members of the ERK and AKT pathways, which are known to be involved in cell cycle progression and cell growth (27-30). GSK-3 $\beta$ is a downstream regulator of the ERK and AKT pathways, the activity of which can be inhibited by serine phosphorylation mediated by AKT or ERK, inducing cell cycle transition from the $\mathrm{G} 1$ to the $\mathrm{S}$ phase $(31,32)$. In the present study knockdown of CEP131 expression decreased the expression of p-PI3K, p-Akt, p-MEK1/2, p-Erk1/2 and p-GSK-3 $\beta$. These results suggest that CEP131 promotes cell proliferation in NSCLC tissue, at least partly, via the activation of the ERK and AKT pathways.

In conclusion, the present study demonstrated that CEP131 expression is upregulated in NSCLC tissues. Additionally, knockdown of CEP131 expression inhibits cell proliferation by inhibiting the ERK and AKT signaling pathways in NSCLC cells. Future studies should perform overexpression experiments in order to confirm these results. Taken together, these findings indicate that CEP131 may be a potential therapeutic target in NSCLC.

\section{Acknowledgements}

Not applicable.

\section{Funding}

No funding was received.

\section{Availability of data and materials}

The datasets used and/or analyzed during the present study are available from the corresponding author on reasonable request.

\section{Authors' contributions}

Study concept and design was undertaken by JW. SH and LZ analyzed and interpreted the data. JW drafted the manuscript. XY critically revised the manuscript for important intellectual content and performed the statistical analysis.

\section{Ethics approval and consent to participate}

Ethical approval was obtained from the Institutional Review Board of Dalian Medical University (Dalian, China). Patients included in the present study provided written informed consent.

\section{Patient consent for publication}

Not applicable.

\section{Competing interests}

The authors declare that they have no competing interests.

\section{References}

1. Baker MJ, Cooke $M$ and Kazanietz MG: Nuclear PKCl-ECT2-Rac1 and ribosome biogenesis: A novel axis in lung tumorigenesis. Cancer Cell 31: 167-169, 2017.

2. Wu DW, Chen TC, Huang HS and Lee H: TC-N19, a novel dual inhibitor of EGFR and cMET, efficiently overcomes EGFR-TKI resistance in non-small-cell lung cancer cells. Cell Death Dis 7: e2290, 2016.

3. Zhang X, Yu X, Jiang G, Miao Y, Wang L, Zhang Y, Liu Y, Fan C, Lin X, Dong Q, et al: Cytosolic TMEM88 promotes invasion and metastasis in lung cancer cells by binding DVLS. Cancer Res 75: 4527-4537, 2015.

4. Wei CC, Nie FQ, Jiang LL, Chen QN, Chen ZY, Chen X, Pan X, Liu ZL, Lu BB and Wang ZX: The pseudogene DUXAP10 promotes an aggressive phenotype through binding with LSD1 and repressing LATS2 and RRAD in non small cell lung cancer. Oncotarget 8: 5233-5246, 2017.

5. Kumar A, Rajendran V, Sethumadhavan R and Purohit R: CEP proteins: The knights of centrosome dynasty. Protoplasma 250: 965-983, 2013.

6. Aoto H, Tsuchida J, Nishina Y, Nishimune Y, Asano A and Tajima S: Isolation of a novel cDNA that encodes a protein localized to the pre-acrosome region of spermatids. Eur J Biochem 234: 8-15, 1995.

7. Aoto H, Miyake Y, Nakamura M and Tajima S: Genomic organization of the mouse AZ1 gene that encodes the protein localized to preacrosomes of spermatids. Genomics 40: 138-141, 1997.

8. Andersen JS, Wilkinson CJ, Mayor T, Mortensen P, Nigg EA and Mann M: Proteomic characterization of the human centrosome by protein correlation profiling. Nature 426: 570-574, 2003.

9. Ma L and Jarman AP: Dilatory is a Drosophila protein related to AZI1 (CEP131) that is located at the ciliary base and required for cilium formation. J Cell Sci 124: 2622-2630, 2011.

10. Staples CJ, Myers KN, Beveridge RD, Patil AA, Lee AJ, Swanton C, Howell M, Boulton SJ and Collis SJ: The centriolar satellite protein Cep131 is important for genome stability. J Cell Sci 125: 4770-4779, 2012.

11. Tollenaere MAX, Villumsen BH, Blasius M, Nielsen JC Wagner SA, Bartek J, Beli P, Mailand N and Bekker-Jensen S: p38- and MK2-dependent signalling promotes stress-induced centriolar satellite remodelling via 14-3-3-dependent sequestration of CEP131/AZI1. Nat Commun 6: 10075, 2015.

12. Li X, Song N, Liu L, Liu X, Ding X, Song X, Yang S, Shan L, Zhou X, Su D, et al: USP9X regulates centrosome duplication and promotes breast carcinogenesis. Nat Commun 8: 14866, 2017.

13. Liu XH, Yang YF, Fang HY, Wang XH, Zhang MF and Wu DC: CEP131 indicates poor prognosis and promotes cell proliferation and migration in hepatocellular carcinoma. Int J Biochem Cell Biol 90: 1-8, 2017.

14. Travis WD, Brambilla E, Nicholson AG, Yatabe Y, Austin JHM, Beasley MB, Chirieac LR, Dacic S, Duhig E, Flieder DB, et al: The 2015 World Health Organization classification of lung tumors: Impact of genetic, clinical and radiologic advances since the 2004 classification. J Thorac Oncol 10: 1243-1260, 2015.

15. Wang H, Yu Z, Huo S, Chen Z, Ou Z, Mai J, Ding S and Zhang J: Overexpression of ELF3 facilitates cell growth and metastasis through PI3K/Akt and ERK signaling pathways in non-small cell lung cancer. Int J Bio Cell Bio 94: 98-106, 2018.

16. Zhao J, Ou B, Han D, Wang P, Zong Y, Zhu C, Liu D, Zheng M, Sun J, Feng $\mathrm{H}$ and Lu A: Tumor-derived CXCL5 promotes human colorectal cancer metastasis through activation of the ERK/Elk-1/Snail and AKT/GSK3 $\beta / \beta$-catenin pathways. Mol Cancer 16: 70, 2017.

17. Wang Y, Nie H, Zhao X, Qin Y and Gong X: Bicyclol induces cell cycle arrest and autophagy in HepG2 human hepatocellular carcinoma cells through the PI3K/AKT and Ras/Raf/MEK/ERK pathways. BMC Cancer 16: 742, 2016. 
18. Hall JR, Messenger ZJ, Tam HW, Phillips SL, Recio L and Smart RC: Long noncoding RNA lincRNA-p21 is the major mediator of UVB-induced and p53-dependent apoptosis in keratinocytes. Cell Death Dis 6: e1700, 2015.

19. Sun L, Song L, Wan Q, Wu G, Li X, Wang Y, Wang J, Liu Z, Zhong $\mathrm{X}$, He $\mathrm{X}$, et al: CMyc-mediated activation of serine biosynthesis pathway is critical for cancer progression under nutrient deprivation conditions. Cell Res 25: 429-444, 2015.

20. Mizuno H, Nakanishi Y, Ishii N, Sarai A and Kitada K: A signature-based method for indexing cell cycle phase distribution from microarray profiles. BMC Genomics 10: 137, 2009.

21. Sherr CJ and Roberts JM: CDK inhibitors: positive and negative regulators of G1-phase progression. Genes Dev 13: 1501-1512, 1999.

22. Tashima $\mathrm{Y}$, Hamada $\mathrm{H}$, Okamoto $\mathrm{M}$ and Hanai T: Prediction of key factor controlling G1/S phase in the mammalian cell cycle using system analysis. J Biosci Bioeng 106: 368-374, 2008.

23. Sherr CJ: Mammalian G1 cyclins. Cell 73: 1059-1065, 1993.

24. Donnellan R and Chetty R: Cyclin D1 and human neoplasia. Mol Pathol 51: 1-7, 1998

25. Zuryn A, Litwiniec A, Safiejko-Mroczka B, KlimaszewskaWiśniewska A, Gagat M, Krajewski A, Gackowska L and Grzanka D: The effect of sulforaphane on the cell cycle, apoptosis and expression of cyclin D1 and p21 in the A549 non-small cell lung cancer cell line. Int J Oncol 48: 2521-2533, 2016.

26. Zhang X, Wu J, Luo S, Lechler T and Zhang JY: FRA1 promotes squamous cell carcinoma growth and metastasis through distinct AKT and c-Jun dependent mechanisms. Oncotarget 23: 34371-34383, 2016.

27. Wang Y, Liu J, Cui J, Xing L, Wang J, Yan X and Zhang X: ERK and p38 MAPK signalling pathways are involved in ochratoxin A-induced G2 phase arrest in human gastric epithelium cells. Toxicol Lett 209: 186-192, 2012.
28. Shao Q, Han F, Peng S and He B: Nur77 inhibits oxLDL induced apoptosis of macrophages via the p38 MAPK signalling pathway. Biochem Biophys Res Commun 471: 633-638, 2016.

29. Chien CC, Wu MS, Shen SC, Ko CH, Chen CH, Yang LL and Chen YC: Activation of JNK contributes to evodiamineinduced apoptosis and G2/M arrest in human colorectal carcinoma cells: A structure-activity study of evodiamine. PLoS One 9: e99729, 2014.

30. Tsai WB, Aiba I, Long Y, Lin HK, Feun L, Savaraj N and Kuo MT: Activation of Ras/PI3K/ERK pathway induces c-Myc stabilization to upregulate argininosuccinate synthetase, leading to arginine deiminase resistance in melanoma cells. Cancer Res 72: 2622-2633, 2012.

31. Saiprasad G, Chitra P, Manikandan R and Sudhandiran G: Hesperidin induces apoptosis and triggers autophagic markers through inhibition of Aurora-A mediated phosphoinositide-3-kinase/Akt/mammalian target of rapamycin and glycogen synthase kinase-3 beta signalling cascades in experimental colon carcinogenesis. Eur J Cancer 50: 2489-2507, 2014.

32. Wen W, Ding J, Sun W, Fu J, Chen Y, Wu K, Ning B, Han T, Huang L, Chen C, et al: Cyclin G1-mediated epithelial-mesenchymal transition via phosphoinositide 3-kinase/Akt signaling facilitates liver cancer progression. Hepatology 55: 1787-1798, 2012.

This work is licensed under a Creative Commons Attribution-NonCommercial-NoDerivatives 4.0 International (CC BY-NC-ND 4.0) License. 